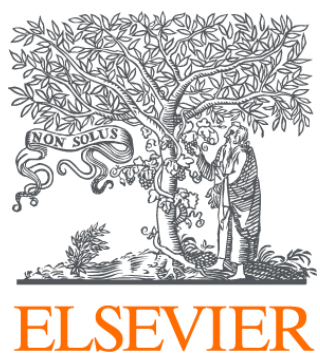

Since January 2020 Elsevier has created a COVID-19 resource centre with free information in English and Mandarin on the novel coronavirus COVID-

19. The COVID-19 resource centre is hosted on Elsevier Connect, the company's public news and information website.

Elsevier hereby grants permission to make all its COVID-19-related research that is available on the COVID-19 resource centre - including this research content - immediately available in PubMed Central and other publicly funded repositories, such as the WHO COVID database with rights for unrestricted research re-use and analyses in any form or by any means with acknowledgement of the original source. These permissions are granted for free by Elsevier for as long as the COVID-19 resource centre remains active. 


\section{The Penumbra}

\section{COVID-19 fault lines}

My daughter's art project, a small ceramic bowl, tipped over the edge of the table and broke into pieces. To assuage her tears, I used what I had on hand, a thin wood glue, to patch it together. It was a rushed effort, but I deemed it good enough for the moment. The bowl hung precariously together until she decided, one day, to fill it with water to bathe a toy. Under that small challenge, the fragile bonds between the pieces gave way. The water dribbled out, and the bowl cracked open.

Within any hospital's emergency room, the fault lines of society are barely concealed. The simple act of discharging someone is one of the hardest things we do in medicine. Homeless shelters fill quickly, especially in cold weather. Domestic violence shelters too. They don't usually have enough resources to handle surges in need. No one would think to provide the luxury of sufficient space and staff to, say, enable the kind of social distancing space between occupants that is recommended in the midst of the coronavirus disease 2019 (COVID-19) pandemic. The gaps in need are patched over with thin, inadequate solutions.

In fact, part of the practice of emergency medicine is constructing the perfect plan and watching it quickly fall apart under social realities. This patient can go home on a course of antibiotics. But what if there's no home, no ability to fill or refrigerate medications? You have no plan. A week or two of rest and immobility is the answer. But what if sick leave means no income, no ability to pay rent or buy food? No plan. Admission to hospital would fix it. But what if, in a country like the USA, the cost of that stay, that operation, that transfer would crush the family financially? No plan.

COVID-19 has exposed these societal fault lines, baring our vulnerabilities. It has also stimulated a modicum of action, with varying degrees of compassion. The city of Las Vegas infamously turned a parking lot into a sleeping area after a homeless shelter closed due to a case of COVID-19, marking squares on the bare ground to enforce social distancing. But in other places, hospitals are admitting stable patients with COVID-19 to avoid discharging them to the street, or hotel rooms and trailers have materialised as extra shelter. The shift to telehealth has meant more accessibility not only for people newly home-bound due to stay-at-home orders but also for those for whom an in-person health visit was never a simple or easy thing, including individuals with disabilities, the elderly, or those without access to transportation. These are successes, and I applaud them. But the imperative to create alternative shelters is driven by the fact that overcrowded shelters and homeless encampments facilitate the spread of disease. The gains to certain populations from virtual visits are an accidental benefit. Where were these initiatives before? Will they vanish once the pandemic is over?
The descriptions of COVID-19 as the "great equaliser" are not quite right, for the illness is hitting some people harder than others. The disease spreads faster in places where social distancing is an impossibility. Its collateral damage is hardest on those with low income. COVID-19 seems to be widening, not narrowing, racial and ethnic health disparities caused by longstanding systemic inequities-for example, Black and Hispanic people in the USA have disproportionately higher rates of hospitalisation and death from COVID-19. Still, the pandemic might make it tougher to pretend that the fate of one corner of society is disconnected from that of another. Anyone who wishes to avoid the spread to less densely populated areas must care about what is happening in big cities. Anyone in a private home who wishes to address the disease's spread must care about what is happening in group homes, nursing homes, and correctional facilities.

It is hard to think forward to a time beyond this immediate moment of crisis. Working in the emergency department, the most pressing issues are who has the disease and who doesn't, and what to do with the patient in front of me. But as we scramble to distribute limited resources such as tests and hospital equipment andultimately-therapies and a vaccine, we must be careful to avoid reinforcing existing fault lines going forward. And all of us lucky enough to get a post-pandemic chapter must revisit those fault lines with urgency, holding each other accountable for remembering how intimately our fates are interconnected, even when we don't have a virus to bring the point home.

\section{Esther K Choo}

Center for Policy and Research in Emergency Medicine, Oregon Health and Science University, Portland, OR 97239, USA chooe@ohsu.edu

@choo_ek

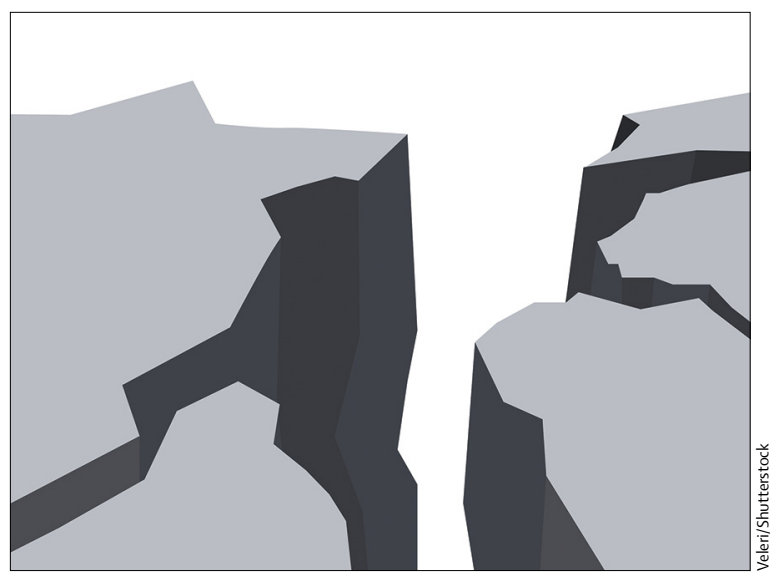

For more on The Penumbra see Comment Lancet 2019; 394: 453 and Perspectives Lancet 2020; 395: 940

Further reading

US Centers for Disease Control and Prevention. Interim guidance for homeless service providers to plan and respond to coronavirus disease 2019 (COVID-19). 2020. https://www. cdc.gov/coronavirus/2019-ncov/ community/homeless-shelters/ plan-prepare-respond.html (accessed April 15, 2020)

Blackstock U. What the COVID-19 pandemic means for Black Americans. Sci Am, April 7, 2020. https://www.scientificamerican com/author/uche-blackstock/ (accessed April 15, 2020)

Rubin R. The challenge of preventing COVID-19 spread in correctional facilities. JAMA 2020; published online April 7 . DOI:10.1001/jama.2020.5427 